\title{
A New Criterion to Optimize ORC Design Performance using Efficiency Correlations for Axial and Radial Turbines
}

\author{
Andrea Lazzaretto* ${ }^{1}$, Giovanni Manente ${ }^{2 *}$ \\ ${ }^{1}$ University of Padova, Department of Industrial Engineering, Via Venezia 1, 35131 Padova, Italy, \\ ${ }^{2}$ University of Padova, Department of Industrial Engineering, Via Venezia 1, 35131 Padova, Italy, \\ Email: andrea.lazzaretto@unipd.it
}

\begin{abstract}
Several studies on Organic Rankine Cycles (ORCs) in the literature search for the optimal cycle parameters and working fluids that maximize the net power output. Only few studies carry out a preliminary turbine design to calculate an accurate value of turbine efficiency, but this is done only after the cycle thermodynamic optimization is performed assuming a fixed and somewhat arbitrary value of turbine efficiency. Instead, a new design optimization procedure of ORCs is proposed here which embeds correlations for the design efficiency of both axial and radial turbines. The correlations are obtained from published data in the literature and use the volumetric expansion ratio $(V R)$ and the size parameter $(V H)$ as performance predictors. While been applied to a selected number of working fluids and single stage turbines, the procedure has a general validity being the correlations applicable to any fluid and turbine type. Results show how the turbine efficiency, and in turn the optimum cycle parameters, are influenced by the fluid properties through the turbine $V H$ and $V R$ values, highlighting that the procedure for working fluid selection cannot ignore the real turbine behaviour. So, the optimum design that is obtained is expected to give a behaviour much closer to reality.
\end{abstract}

Keywords: Organic Rankine Cycle; synthesis/design optimization; turbine design; working fluid selection; power generation.

\section{Introduction}

Papers in the literature about Organic Rankine Cycles (ORCs) mainly deal with the search for working fluids and thermodynamic parameters that maximize a thermodynamic objective function, namely the thermal efficiency [1]-[3] or the power output [4], [5]. Additional parameters related to the design of the main system components (heat exchangers, turbines, etc.) are generally evaluated after the maximization of the thermodynamic objective function [6]-[9].

Saleh et al. in [6] calculated the values of the volumetric flow rate at the inlet of the turbine $\dot{V}_{\text {in }}$ (with reference to a power output of $1 \mathrm{MW}$ ) and the ratio between turbine outlet and inlet volumetric flow rates $\dot{V}_{\text {out }} / \dot{V}_{\text {in }}$. They emphasized that the best fluids should give both high thermal efficiencies and low values of $\dot{V}_{\text {in }}$ and $\dot{V}_{\text {out }} / \dot{V}_{\text {in }}$ for a proper turbine design. A similar approach was pursued in [3] to comparatively assess the working fluids performance in low-temperature solar organic Rankine cycle systems using $\dot{V}_{\text {out }}$ and $\dot{V}_{\text {out }} / \dot{V}_{\text {in }}$ as evaluation parameters. In [10] the performance of three mixtures of R245fa and R152a having the following compositions in terms of mass fractions $(0.9 / 0.1,0.65 / 0.35,0.45 / 0.55)$ was analyzed. The authors found that none of the mixtures held the highest thermal efficiency, the lowest $\dot{V}_{\text {in }}$ and the lowest $\dot{V}_{\text {out }} / \dot{V}_{\text {in }}=v_{\text {out }} / v_{\text {in }}$ at the same time. However, in all of these studies the calculation of the turbine volumetric flow rates were only used to give some qualitative information and they were not directly linked to the efficiency or size of the turbines.
One of the few recent studies that used thermodynamic parameters to give quantitative information on the turbine design was performed in [11]. The values of $\dot{V}_{\text {out }}$ and the isentropic enthalpy drop $\Delta h_{\text {is }}$ obtained by the thermodynamic cycle optimization were used to evaluate the turbine diameter $(D)$, starting from a value of specific diameter $\left(d_{s}\right)$ associated with a high radial turbine efficiency. A R245fa ORC system was compared against an isopentane ORC system for two heat source temperatures of $90^{\circ} \mathrm{C}$ and $120^{\circ} \mathrm{C}$. Although the power output of isopentane was 0.5 to $4 \%$ points higher than R245fa, the isopentane turbine diameter was $11-12 \%$ larger, so that R245fa was finally preferred.

Marcuccilli and Thiolet in [8] performed an extensive survey of different working fluids to calculate the best cycle thermal efficiency and to choose the most suitable fluids for radial turbine operation. Similarly to [11] they calculated the turbine diameter from $\Delta h_{\text {is }}$ and $\dot{V}_{\text {out }}$, but using a proprietary formula (not shown in the paper) of the manufacturer. They ranked the working fluids on the basis of a performance factor $(P F)$, proportional to the thermal efficiency and inversely proportional to the square of the turbine diameter $(D): P F=\eta_{t h} / D^{2}$. Both [8] and [11] used the thermodynamic parameters in the expansion process only to calculate the size of the turbine, but they did not supply any information about the efficiency effectively achievable by turbines working under these cycle parameters. 
The variation of total to static turbine efficiency with thermodynamic cycle parameters was taken into account in [12]. First the optimal cycle parameters were calculated for five different working fluids (R134a, R143a, R236fa, R245fa and n-pentane) assuming a fixed turbine efficiency (85\%). Then, a preliminary design of the turbines was performed to calculate its efficiency starting from the optimal cycle parameters and using the commercial software RITAL, which includes the one-dimensional meanline design procedure proposed by Moustapha et al. in [13]. Although the flow and loading coefficients were set for all fluids equal to the optimal ones for radial turbines suggested in [14], the calculated turbine efficiencies for the various working fluids were quite different (ranging from 0.75 to 0.785 ) and deviated substantially from the assumed value of 0.85 . However, no explanation was given by the authors about how the specific fluid properties influence the turbine losses calculated by RITAL (and consequently the turbine efficiency), nor on the need of re-calculating the optimal cycle thermodynamic cycle parameters on the basis of these findings.

A different and new approach is suggested here, in which the evaluation of the turbine isentropic efficiency is directly embedded in the thermodynamic cycle optimization. This approach requires correlations for the turbine isentropic efficiency to be defined based on the cycle parameters calculated by the thermodynamic analysis. In this paper correlations obtained from published maps available in the literature [15], [16] linking turbine isentropic efficiency to $\dot{V}_{\text {out }} / \dot{V}_{\text {in }}$ and $\dot{V}_{\text {out }}^{0.5} / \Delta h_{\text {is }}^{0.25}$, are included in the thermodynamic cycle optimization. These maps were created for both axial flow and radial flow turbine stages. The availability of specific and updated maps for the turbine being considered (see, e.g., the new efficiency prediction map for single-stage axial turbines [17] shown at the $2^{\text {nd }}$ International Seminar on ORC Power Systems) may improve the accuracy of the results, but do not affect the general validity of the suggested procedure, being these maps valid for any kind of fluid. The purpose of this approach is to find the values of the cycle parameters corresponding to maximum net power output considering the isentropic efficiency effectively achievable by the turbine.

\section{Axial and radial turbine design}

Axial and radial turbines are both used in practical applications of Organic Rankine Cycle systems. A radial turbine stage can deliver a greater specific power than an equivalent axial stage, and this may imply smaller and/or fewer stages in a machine (see [14]). The enthalpy drop in the expansion processes of Organic Rankine Cycles is lower than the steam enthalpy drop over the same temperature interval owing to the use of heavy substances as working fluids [18]. Thus, in many low temperature applications the work transfer can be simply achieved by using an axial stage [19]. The isentropic efficiency of both axial and radial turbines can be correlated with the specific speed $N_{S}$ :

$$
N_{S}=\omega \frac{\dot{V}_{\text {out }}^{0.5}}{\Delta h_{\text {is }}^{0.75}}
$$

It is shown [20] that the best efficiency of axial turbines occur at high specific speed $(>0.3)$ whereas radial turbines show the best efficiencies in the range of $N_{S}$ between about $0.4 \div 0.8$ (where $\omega$ is expressed in $\mathrm{rad} / \mathrm{s}$ ). The use of an appropriate specific speed does not directly imply that a high efficiency design will result. The specific speed specific diameter chart [21] clearly shows that the specific diameter $d_{s}$, defined by:

$d_{s}=\frac{D \cdot \Delta h_{\text {is }}^{0.25}}{\dot{V}_{\text {out }}^{0.5}}$

is an additional variable that strongly affects the turbine efficiency at fixed specific speed. The best designs lay along the Cordier line [13], [21]. A high efficiency turbine design should provide both a specific speed in the optimal range and the corresponding optimal specific diameter (note that the efficiency prediction maps in [15]-[17] assume the possibility of designing the turbine at optimum values of $N_{S}$ and $d_{s}$ ). The selection of specific speed can therefore lead immediately to the choice of the appropriate specific diameter, and hence to the actual diameter [11].

The specific speed and diameter correlations are often dated and may not represent modern turbine technology. Data on which they are based are usually not available and their application is questionable for high pressure ratios and real gases [22]. Specific speed is a guide to turbine type and overall size but gives no further information. To progress, it is helpful to use design coefficients such as stage loading coefficient $(\psi)$ and flow coefficient $(\phi)$ defined respectively by:

$$
\begin{gathered}
\psi=\frac{\Delta h_{0}}{U^{2}} \\
\phi=\frac{C_{m}}{U}
\end{gathered}
$$

The efficiency of both axial and radial turbine stages can be correlated with the flow coefficient and the stage loading coefficients. The Smith chart is a widely used efficiency correlation for axial flow turbines [14], [20]. It shows that for best efficiency both the stage loading and the flow coefficients must be low. A similar chart linking turbine efficiency with blade loading and flow coefficients was obtained for radial turbines [13], [14] using test data taken from a wide variety of stage designs. It shows that maximum radial turbine efficiency occurs at loading coefficients between about 0.9 and 1.0 and flow coefficients in the range $0.2 \div 0.3$. Note that the blade loading coefficient for radial turbines is based on the inlet blade speed.

With these duty parameters defined ( $\psi$ and $\phi$ ) the key geometric parameters follow, namely passage areas and blade heights and blade angles at inlet and outlet of the turbine. Using this information and a good one-dimensional turbine model it is possible to estimate turbine efficiency with confidence.

Sauret and Rowlands in [12] performed the preliminary design of radial turbines for five selected fluids (R134a, R143a, R236fa, R245fa, n-pentane). The loading and flow coefficients were set for all fluids at 0.918 and 0.215 , respectively, searching for the best turbine efficiency according to the chart in [13], [14]. The resulting turbine 
isentropic efficiency varied from $75.0 \%$ for R236fa to 78.5\% for R143a. Thus, although the stage loading and flow coefficients were fixed for all fluids at the same optimal values, still some differences arose in the isentropic efficiencies (within 2.5 percentage points). These differences are ascribable to the fluid properties and should be directly taken into account in the thermodynamic cycle analysis. However, a rather detailed turbine design would be impractical in thermodynamic analyses which must consider several possible thermodynamic cycles and turbines.

Macchi and Perdichizzi [15] proposed a method which allows for a simple efficiency prediction of an axial turbine stage operating with organic fluids. A similar procedure was applied by Perdichizzi and Lozza in [16] to correlate the efficiency of radial inflow turbines. The turbine stage efficiency was correlated with the specific volume variation across the turbine and a dimensional parameter which accounts for actual turbine dimensions. The axial flow turbine efficiency prediction method was further developed in [23] and successfully compared against data of real ORC engines. Angelino et al. [23] clearly show that the efficiency of an axial flow turbine stage of good aerodynamic design is influenced not only by the parameters which can be optimally set by the turbine designer (namely $N_{S}, \psi$ ), but it also depends on the volumetric expansion ratio (VR) and the size parameter $(\mathrm{VH})$ which can be regarded as thermodynamic data that are set only by the working fluid properties, the thermodynamic cycle and the power output:

$$
V R=\frac{\dot{V}_{\text {out }}}{\dot{V}_{\text {in }}}
$$

$$
V H=\frac{\dot{V}_{o u t}^{0.5}}{\Delta h_{i s}^{0.25}}
$$

The volumetric expansion ratio was found to be a more meaningful parameter (in place of the pressure ratio) to correlate the degradation of turbine efficiency with the expansion ratio for different substances. The size parameter is obtained from the similarity rules and accounts for the size of the turbines. Similar turbines having the same $V H$ have the same actual dimensions (see [15]). It is well known that small turbines show lower efficiencies compared to large turbines (due to the larger relative thickness, clearance etc.) and the correlation with $\mathrm{VH}$ accounts for all of these aspects.

Figures $1 \mathrm{a}$ and $1 \mathrm{~b}$ show the variation with $V H$ and $V R$ of optimum specific speed and turbine isentropic efficiency (at optimum specific speed) for axial flow turbines. Note that the specific speed in the following charts (Figures 1 and 2; Figures 6 and 7; Table 6) is defined by Eq. (1) with $\omega$ expressed in rps (revolutions per second) rather than in rad/s. The optimum specific speed increases from 0.07 to 0.15 when the system size and volumetric expansion ratio are reduced. The iso-efficiency lines are oblique in the plane $V H-V R$. The same turbine efficiency can be achieved at low $(V H ; V R)$ or at high $(V H ; V R)$. The maximum isentropic efficiencies approach $90 \%$ and occur at high $V H$ and low VR.

Similarly, Figures 2a and 2b show the correlations with $V H$ and $V R$ of optimum specific speed and turbine isentropic efficiency (at optimum specific speed) for radial inflow turbines. The optimum specific speeds vary between 0.080 and 0.120 and show a different trend compared to axial flow turbines: at fixed $V R$ the optimum specific speed varies only slightly in the range $0.05<V H<0.20$ and it decreases when $V H$ is further reduced below 0.05. The maximum efficiency is lower compared to axial turbines but remains high even at quite high values of $V R$.
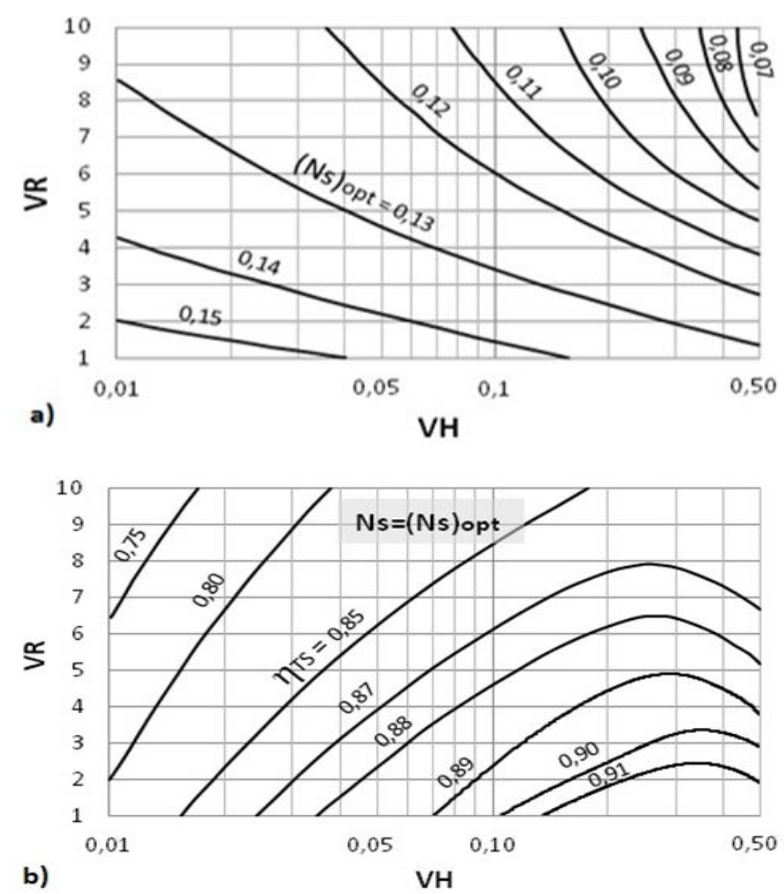

Figure 1. Efficiency prediction for an AXIAL turbine stage: a) Optimum specific speed as a function of $V H$ and $V R ; b$ ) Turbine isentropic efficiency at optimum specific speed as a function of VH and VR. (reproduced from [15]).
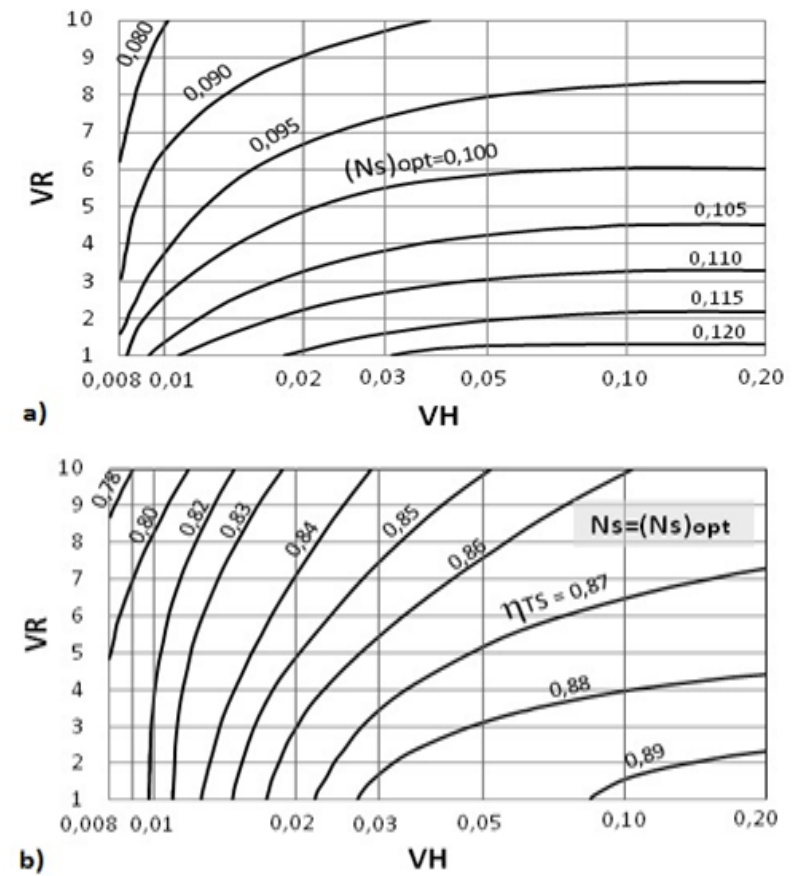

Figure 2. Efficiency prediction for a RADIAL turbine stage: a) Optimum specific speed as a function of $\mathrm{VH}$ and $V R$; b) Turbine isentropic efficiency at optimum specific speed as a function of VH and VR. (reproduced from [16]) 
These correlations (Figures 1 and 2) are used in this paper for the calculation of turbine efficiency and optimum specific speed in the thermodynamic analysis and optimization of Organic Rankine Cycles. The charts are fitted by a 3-D surface using a multiple linear regression technique to obtain the following correlations for both single-stage axial and radial turbines:

$\eta_{\text {is }}=f(V R, V H)$

$(N s)_{o p t}=f(V R, V H)$

The underlying assumption when using these charts is that both single stage axial turbines and radial turbines are suitable for the present application and that it is possible to operate at the optimal specific speed by properly selecting the rotational speed. Note that although axial flow turbines may result in higher efficiencies at design point, radial inflow turbines may be preferred and are widely adopted in recently built power plants (see e.g., [24]) due to their better performance at off-design conditions achievable using variable inlet guide vanes.

\section{Thermodynamic optimization embedding turbine efficiency evaluation \\ 3.1 The simulation model and main assumptions}

The simulation model was built in the Aspen Plus ${ }^{\circledR}$ environment. Figure 3 shows the plant configuration: the power plant is composed by five main components: feed pump, preheater, vaporizer, turbine and condenser. The cycle configuration is non-regenerative. The working fluid is preheated and vaporized by heat transfer with the geothermal fluid (pressurized water). The turbine inlet temperature is assumed $1^{\circ} \mathrm{C}$ higher than the saturation temperature at the cycle maximum pressure. The working fluid mass flow rate is calculated by assuming a minimum temperature difference of $10^{\circ} \mathrm{C}$ between geothermal fluid and working fluid. Two geothermal fluid mass flow rates $(100 \mathrm{~kg} / \mathrm{s}$ and $10 \mathrm{~kg} / \mathrm{s})$ are considered. While only axial turbine designs are analyzed in the former case $(100 \mathrm{~kg} / \mathrm{s})$, both axial and radial turbine designs are evaluated in the latter case $(10 \mathrm{~kg} / \mathrm{s})$, as shown in Figure 3. It is assumed that optimum specific speeds (Figures 1a and 2a) can be achieved for any operating condition by varying the rotational speed so that the turbine isentropic efficiencies are directly calculated from the charts in Figures $1 \mathrm{~b}$ and $2 \mathrm{~b}$.

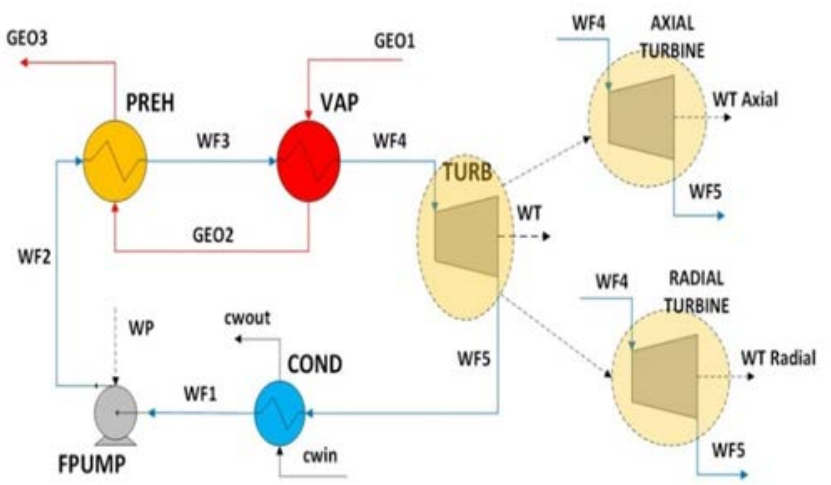

Figure 3. Flowsheet of the Organic Rankine Cycle
Table 1. Main assumptions of the simulation model.

\begin{tabular}{ll}
\hline Parameter & Value \\
\hline Geofluid mass flow rate, & $100 \mathrm{~kg} / \mathrm{s}$ Axial \\
$m_{G E O}$ & $10 \mathrm{~kg} / \mathrm{s} \mathrm{Axial} \mathrm{and} \mathrm{Radial}$ \\
Geofluid inlet temperature & $150^{\circ} \mathrm{C}$ \\
$\Delta T m i n$ & $10^{\circ} \mathrm{C}$ \\
$T$ turbine inlet & $T$ sat $+1^{\circ} \mathrm{C}$ \\
$\eta$ is Axial & Calculated from Figure $1 \mathrm{~b}$ \\
$\eta$ is Radial & Calculated from Figure $2 \mathrm{~b}$ \\
Mech/Gen efficiency & $98 \%$ \\
Pump efficiency & $80 \%$ \\
$T$ condensing & $35^{\circ} \mathrm{C}$ \\
\hline
\end{tabular}

Four working fluids were taken into account: iC4 (isobutane), R245fa, R236fa, R236ea. Critical temperatures $\left(T_{C R}\right)$ and critical pressures $\left(p_{C R}\right)$ are shown in Table 2 . The critical temperatures of the selected working fluids are close to the inlet temperature of the heat source in order to maximize the power output.

\section{Table 2. Fluid critical temperature and critical pressure.}

\begin{tabular}{lcc}
\hline Fluid & $T_{C R}\left({ }^{\circ} \mathrm{C}\right)$ & $p_{C R}($ bar $)$ \\
\hline Isobutane & 134.7 & 36.4 \\
R245fa & 154.1 & 36.4 \\
R236fa & 124.9 & 32.2 \\
R236ea & 139.2 & 34.1 \\
\hline
\end{tabular}

The net power output $\left(P_{n e t}\right)$, that is defined as the difference between the power generated by the turbine $\left(P_{\text {turb }}\right)$ and the power absorbed by the feed pump $\left(P_{\text {pump }}\right)$ was maximized by varying the cycle maximum pressure.

\subsection{Simulation results}

Figures $4 \mathrm{a}$ and $4 \mathrm{~b}$ show the variation of net power output with the cycle maximum pressure for a geothermal mass flow rate of $100 \mathrm{~kg} / \mathrm{s}$ and $10 \mathrm{~kg} / \mathrm{s}$, respectively. Solid and dotted lines in Figure $4 \mathrm{~b}$ refer to axial and radial turbine design respectively. Tables $3 a$, $3 b$ and 3c show the corresponding values of the maximum net power output for each working fluid. The highest net power output is achieved by R236fa: for a geothermal mass flow rate of 100 $\mathrm{kg} / \mathrm{s}$ the maximum net power output approaches $4 \mathrm{MW}$. The fluid R245fa gives the worst performance (3.57 MW). When the geothermal mass flow rate is reduced to $10 \mathrm{~kg} / \mathrm{s}$ the fluid ranking does not change but the net power output decreases more than 10 times because of the decrease in turbine efficiency associated with the lower turbine size. Moreover, Figure 4b shows that radial turbines (dotted lines) perform slightly better than the axial ones (solid lines) at high $p_{\max }$.

Table 4 shows the optimal cycle parameters. These refer to $100 \mathrm{~kg} / \mathrm{s}$ but they can be considered representative of 10 $\mathrm{kg} / \mathrm{s}$ as well being the difference in the optimum thermodynamic parameters rather small. The optimum thermodynamic cycles of R245fa and R236fa are shown in the $T$-s diagrams in Figure 5. The thermodynamic properties of R236fa allows both a high thermal efficiency and an effective cooling of the heat source, which results in the highest system efficiency and net power output. The turbine inlet temperature of R236fa is the highest $\left(100.8^{\circ} \mathrm{C}\right)$ and the geofluid outlet temperature is the lowest $\left(65.3^{\circ} \mathrm{C}\right)$ among the considered fluids. 
The critical temperature of R236fa is $25^{\circ} \mathrm{C}$ lower than the inlet temperature of the geothermal fluid. This higher temperature gap compared to the other fluids results in a higher optimum evaporation pressure that is closer to the critical pressure. Nonetheless the next section will show that these operating conditions are detrimental from the turbine efficiency point of view due to the higher pressure ratio.
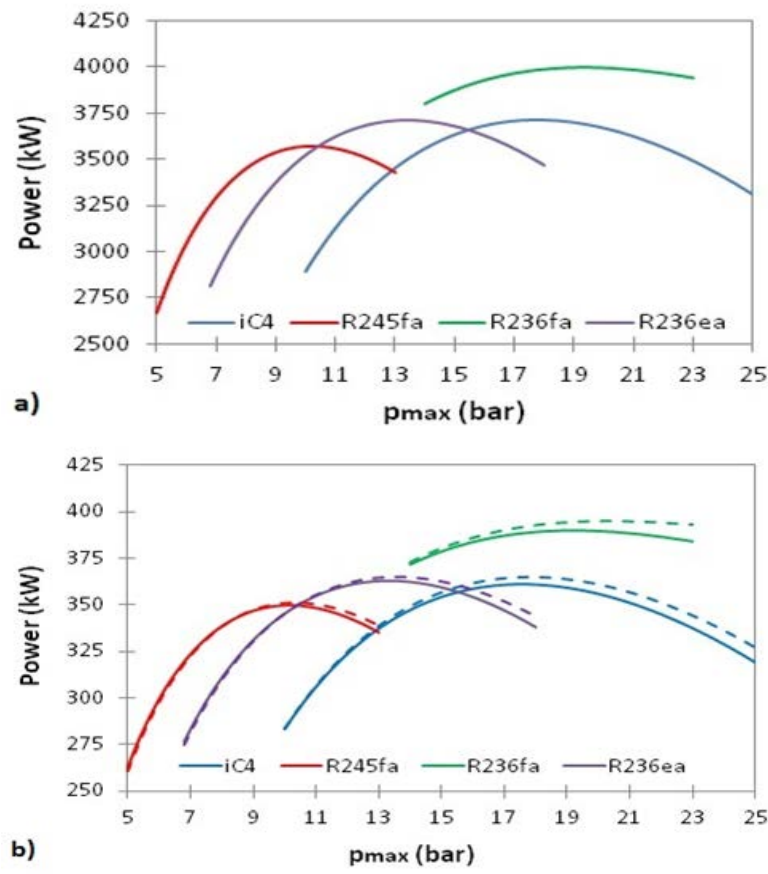

Figure 4. Variation of net power output with cycle maximum pressure: a) $m_{G E O}=100 \mathrm{~kg} / \mathrm{s}$; b) $m_{G E O}=10 \mathrm{~kg} / \mathrm{s}$.

Table 3a. Turbine power, feed pumps power and maximum net power for $100 \mathrm{~kg} / \mathrm{s}$, axial turbine.

\begin{tabular}{lllll}
\hline & iC4 & R245fa & R236fa & R236ea \\
\hline$P_{\text {turb }}$ & 3980.5 & 3684.9 & 4303.4 & 3886.0 \\
$P_{\text {pump }}$ & 268.0 & 114.4 & 307.1 & 175.2 \\
$P_{\text {net }}$ & 3712.4 & 3570.6 & 3996.3 & 3710.8 \\
\hline
\end{tabular}

Table $3 b$. Turbine power, feed pumps power and maximum net power for $10 \mathrm{~kg} / \mathrm{s}$, axial turbine.

\begin{tabular}{lllll}
\hline & iC4 & R245fa & R236fa & R236ea \\
\hline$P_{\text {turb }}$ & 387.6 & 361.1 & 420.4 & 380.3 \\
$P_{\text {pump }}$ & 26.6 & 11.4 & 30.6 & 17.4 \\
$P_{\text {net }}$ & 361.0 & 349.7 & 389.9 & 362.9 \\
\hline
\end{tabular}

Table 3c. Turbine power, feed pumps power and maximum net power for $10 \mathrm{~kg} / \mathrm{s}$, radial turbine.

\begin{tabular}{lllll}
\hline & iC4 & R245fa & R236fa & R236ea \\
\hline$P_{\text {turb }}$ & 391.7 & 362.5 & 426.9 & 382.6 \\
$P_{\text {pump }}$ & 26.8 & 11.4 & 31.9 & 17.6 \\
$P_{\text {net }}$ & 364.9 & 351.1 & 394.9 & 364.9 \\
\hline
\end{tabular}

Table 4. Optimum thermodynamic parameters.

\begin{tabular}{lcccccccc}
\hline & \multicolumn{2}{c}{ iC4 } & \multicolumn{2}{c}{ R245fa } & \multicolumn{2}{c}{ R236fa } & \multicolumn{2}{c}{ R236ea } \\
\hline & $\begin{array}{c}p \\
(\mathrm{bar})\end{array}$ & $\begin{array}{c}T \\
\left({ }^{\circ} \mathrm{C}\right)\end{array}$ & $\begin{array}{c}p \\
(\mathrm{bar})\end{array}$ & $\begin{array}{c}T \\
\left({ }^{\circ} \mathrm{C}\right)\end{array}$ & $\begin{array}{c}p \\
(\mathrm{bar})\end{array}$ & $\begin{array}{c}T \\
\left({ }^{\circ} \mathrm{C}\right)\end{array}$ & $\begin{array}{c}p \\
(\mathrm{bar})\end{array}$ & $\begin{array}{c}T \\
\left({ }^{\circ} \mathrm{C}\right)\end{array}$ \\
\hline WF1 & 4.65 & 35.0 & 2.12 & 35.0 & 3.76 & 35.0 & 2.88 & 35.0 \\
WF2 & 17.8 & 36.0 & 10.2 & 35.4 & 19.3 & 36.0 & 13.4 & 35.6 \\
WF3 & 17.8 & 94.2 & 10.2 & 90.6 & 19.3 & 99.8 & 13.4 & 92.7 \\
WF4 & 17.8 & 95.2 & 10.2 & 91.6 & 19.3 & 100.8 & 13.4 & 93.7 \\
WF5 & 4.65 & 48.8 & 2.12 & 49.1 & 3.76 & 51.0 & 2.88 & 53.7 \\
GEO1 & 15.0 & 150.0 & 15.0 & 150.0 & 15.0 & 150.0 & 15.0 & 150.0 \\
GEO2 & 15.0 & 104.2 & 15.0 & 100.6 & 15.0 & 109.8 & 15.0 & 102.7 \\
GEO3 & 15.0 & 71.3 & 15.0 & 73.4 & 15.0 & 65.3 & 15.0 & 69.1 \\
\hline
\end{tabular}

Table 5. Optimum mass flow rates.

\begin{tabular}{lccccc}
\hline Turbine & $m_{G E O}$ & iC4 & R245fa & R236fa & R236ea \\
\hline Axial & 100 & 85.94 & 145.41 & 205.4 & 181.8 \\
Axial & 10 & 8.65 & 14.54 & 20.57 & 18.26 \\
Radial & 10 & 8.59 & 14.54 & 20.19 & 18.10 \\
\hline
\end{tabular}
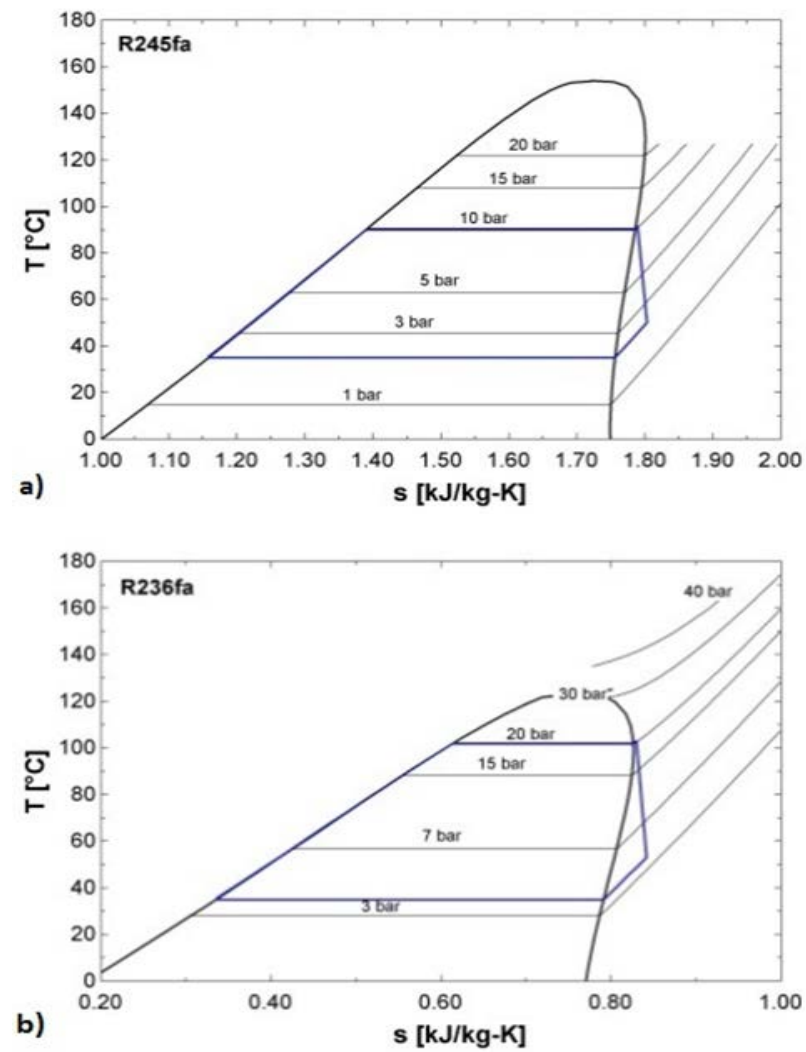

Figure 5. Optimal thermodynamic cycles in T-s diagrams of: a) R245fa; b) R236fa.

\subsection{Turbine design results}

Tables 6a, 6b and 6c show the main parameters associated with the expansion processes in the optimal cycles. The optimum working points are shown as bigger circles in the $V H-V R$ diagrams of Figures 6 and 7.

Geofluid mass flow rate: $100 \mathrm{~kg} / \mathrm{s}$, Axial turbine: Depending on the working fluid being considered, the volumetric flow rate varies between 7.6 and $12.9 \mathrm{~m}^{3} / \mathrm{s}$,

whereas the isentropic enthalpy drop varies between $24.3 \mathrm{~kJ} / \mathrm{kg}$ and $53.1 \mathrm{~kJ} / \mathrm{kg}$. The highest pressure ratio (5.13) and volumetric expansion ratio (6.56) are obtained with R236fa, whereas the lowest pressure ratio and volumetric expansion ratio with isobutane. The highest size parameter (0.275) is associated with R245fa, the lowest with isobutane.

The turbine efficiencies resulting from the combined effects of $V H$ and $V R$ are shown in the last row of Table 6a. The highest value (approaching 0.890 ) is achieved by isobutane and R245fa, the lowest (0.879) by R236fa, which shows the highest volumetric expansion ratio. Sauret and Rowlands [12] found similar results but lower absolute values (e.g., 75\% for R236fa). The higher isentropic enthalpy drop of isobutane compared to the other working fluids requires a higher rotational speed $(n)$ to achieve the optimum specific speed. 
Geofluid mass flow rate: $10 \mathrm{~kg} / \mathrm{s}$, Axial turbine: The lower volumetric flow rate implies lower values of the size parameter which varies between 0.058 and 0.087 (Table $6 \mathrm{~b})$. Thus, the optimum working points in the $V H-V R$ diagrams (Figures 6a and 6b) are shifted to the left and lay on isentropic efficiency lines that are on the average $2 \%$ points lower than using $100 \mathrm{~kg} / \mathrm{s}$ (see Figure 6b). The highest axial turbine isentropic efficiency (0.872) is achieved by R245fa which shows the highest size parameter and a moderate volumetric flow ratio. The isentropic efficiency of isobutane is markedly reduced due to its low $V H$. The high value of $V R$ reduces the turbine efficiency of R236fa also in this case. The low volumetric flow rates at turbine outlet require high rotational speeds to achieve the optimum specific speeds. The combined effect of a high isentropic enthalpy drop and low volumetric flow rate of isobutane results in a rotational speed higher than the practical limit (24,000 rpm according to [12]).

Geofluid mass flow rate: $10 \mathrm{~kg} / \mathrm{s}$, Radial turbine: The lower optimum specific speed of radial turbines results in lower rotational speed than in axial turbines (see Table 6c). The isentropic efficiencies are instead higher because the penalties associated with high $V R$ values are reduced. The optimum working points are shown in Figures $7 \mathrm{a}$ and $7 \mathrm{~b}$.

Table 6a. Axial turbine design parameters for the optimal cycles. $m_{G E O}=100 \mathrm{~kg} / \mathrm{s}$.

\begin{tabular}{lcccc}
\hline & iC4 & R245fa & R236fa & R236ea \\
\hline$\dot{V}_{\text {out }}\left(\mathrm{m}^{3} / \mathrm{s}\right)$ & 7.645 & 12.866 & 8.780 & 10.451 \\
$\Delta h_{\text {is }}(\mathrm{kJ} / \mathrm{kg})$ & 53.13 & 29.06 & 24.32 & 24.54 \\
$p_{\text {ratio }}$ & 3.83 & 4.82 & 5.13 & 4.65 \\
$V R$ & 4.359 & 5.061 & 6.565 & 5.201 \\
$V H$ & 0.1821 & 0.2747 & 0.2373 & 0.2583 \\
$\left(N_{S}\right)_{\text {opt }}$ & 0.1195 & 0.1102 & 0.1031 & 0.1102 \\
$n(\mathrm{rpm})$ & 9077 & 4101 & 4067 & 4009 \\
$\eta_{\text {is }}$ & 0.8898 & 0.8899 & 0.8794 & 0.8888 \\
\hline
\end{tabular}

Table 6b. Axial turbine design parameters for the optimal cycles. $m_{G E O}=10 \mathrm{~kg} / \mathrm{s}$.

\begin{tabular}{lcccc}
\hline & iC4 & R245fa & R236fa & R236ea \\
\hline$\dot{V}_{\text {out }}\left(\mathrm{m}^{3} / \mathrm{s}\right)$ & 0.7718 & 1.289 & 0.8816 & 1.051 \\
$\Delta h_{\text {is }}(\mathrm{kJ} / \mathrm{kg})$ & 52696 & 29056 & 24252 & 24422 \\
$p_{\text {ratio }}$ & 3.79 & 4.82 & 5.11 & 4.62 \\
$V R$ & 4.310 & 5.072 & 6.532 & 5.165 \\
$V H$ & 0.0580 & 0.0870 & 0.0752 & 0.0820 \\
$\left(N_{S}\right)_{\text {opt }}$ & 0.1305 & 0.1238 & 0.1203 & 0.1241 \\
$n(\mathrm{rpm})$ & 31011 & 14561 & 14935 & 14184 \\
$\eta_{\text {is }}$ & 0.8672 & 0.8722 & 0.8598 & 0.8703 \\
\hline
\end{tabular}

Table 6c. Radial turbine design parameters for the optimal cycles. $m_{G E O}=10 \mathrm{~kg} / \mathrm{s}$.

\begin{tabular}{lcccc}
\hline & iC4 & R245fa & R236fa & R236ea \\
\hline$\dot{V}_{\text {out }}\left(\mathrm{m}^{3} / \mathrm{s}\right)$ & 0.7659 & 1.289 & 0.8646 & 1.043 \\
$\Delta h_{\text {is }}(\mathrm{kJ} / \mathrm{kg})$ & 53128 & 29056 & 24875 & 24663 \\
$p_{\text {ratio }}$ & 3.83 & 4.82 & 5.37 & 4.68 \\
$V R$ & 4.367 & 5.070 & 7.015 & 5.255 \\
$V H$ & 0.0576 & 0.0870 & 0.0740 & 0.0815 \\
$\left(N_{S}\right)_{\text {opt }}$ & 0.1051 & 0.1031 & 0.0977 & 0.1025 \\
$n(\mathrm{rpm})$ & 25208 & 12127 & 12481 & 11856 \\
$\eta_{\text {is }}$ & 0.8754 & 0.8755 & 0.8672 & 0.8745 \\
\hline
\end{tabular}

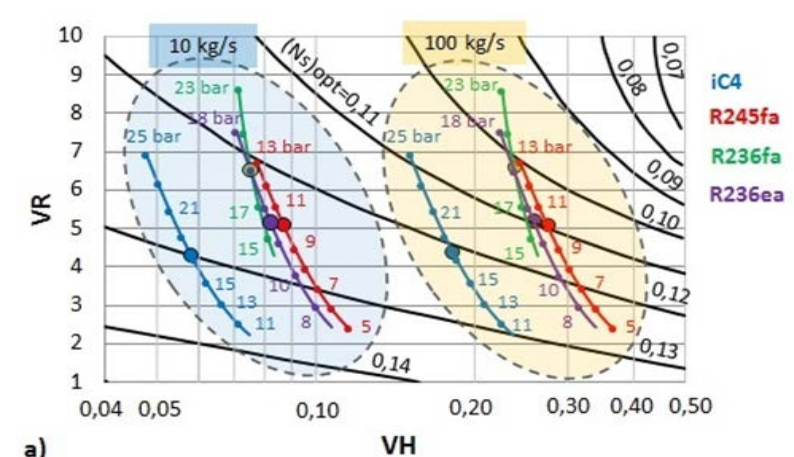

a)

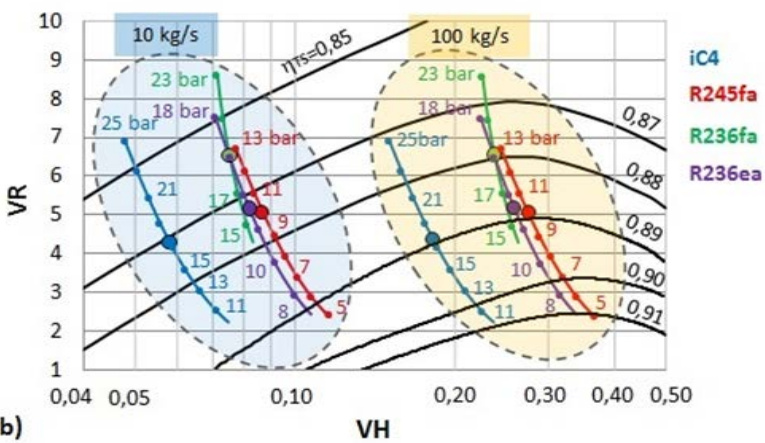

Figure 6. Variation of optimum specific speed (6a) and turbine isentropic efficiency (6b) with VH and VR for an AXIAL turbine stage. The operating conditions maximizing the net power output are shown with a bigger circle.

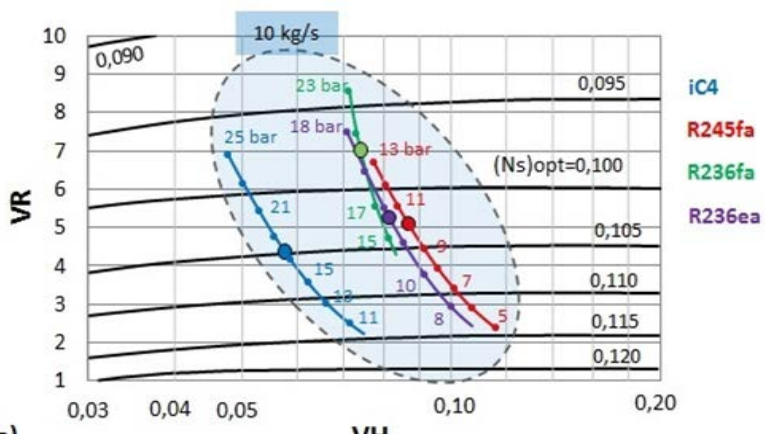

a)

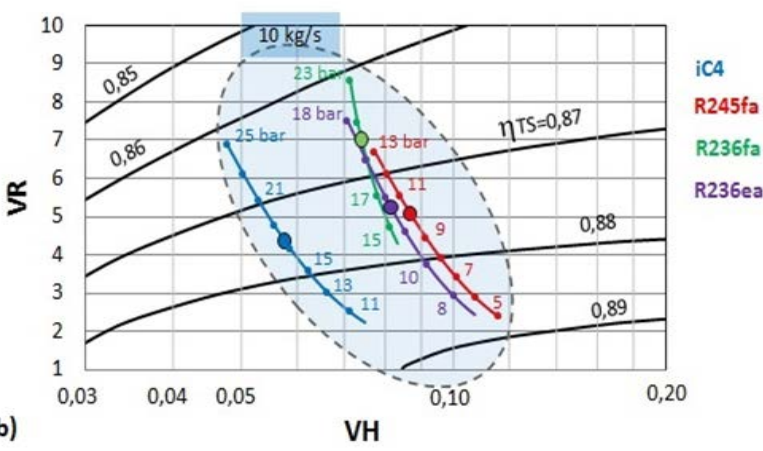

Figure 7. Variation of optimum specific speed (7a) and turbine isentropic efficiency (7b) with $\mathrm{VH}$ and $\mathrm{VR}$ for a RADIAL turbine stage. The operating conditions maximizing the net power output are shown with a bigger circle. 
The lines superimposed on the $V H$-VR charts in Figures 6 and 7 show the variations of optimum specific speed and isentropic efficiency for axial and radial turbines when the cycle maximum pressure deviates from the optimum value (shown with a bigger circle). The increase in maximum pressure is accompanied by both an increase of $V R$ and a reduction of $\mathrm{VH}$, concurring both to the reduction of the turbine efficiency. On the other hand, the decrease of the maximum pressure from the optimum would imply higher turbine efficiency but it would deteriorate the efficiency of the thermodynamic cycle, and in turn the system efficiency. Figures 6 and 7 clearly show that the variation of turbine efficiency with the cycle maximum pressure depends on several factors: the operating conditions, the working fluid and the turbine design. This variation can be more significant for turbines working at low $\mathrm{VH}$ than at high $\mathrm{VH}$ or vice versa depending on the working fluid (see the two set of four lines referring to axial turbines and $100 \mathrm{~kg} / \mathrm{s}$ and $10 \mathrm{~kg} / \mathrm{s}$ respectively in Figure 6b); the slope of the variable pressure lines varies with the working fluid and can be more or less orthogonal to the lines of constant efficiency; the radial turbine design can accommodate a higher volumetric expansion ratio with only small efficiency penalties (compare the green lines referring to R236fa and $10 \mathrm{~kg} / \mathrm{s}$ for the axial turbine, Figure $6 \mathrm{~b}$, and radial turbine, Figure 7b).

\subsection{Influence of the correlation of turbine efficiency on the thermodynamic optimum}

The inclusion of a correlation in the thermodynamic model of ORCs linking turbine isentropic efficiency with $V R$ and $V H$ alters the optimum cycle maximum pressure compared to thermodynamic models where it is instead kept fixed irrespective of working fluids and operating conditions. Figure 8 shows the variation of net power output (left y-axis) and turbine isentropic efficiency (right y-axis) with maximum pressure for all working fluids considered and with reference to a geothermal mass flow rate of $10 \mathrm{~kg} / \mathrm{s}$. The solid lines refer to the net power output calculated using the correlation for axial turbine efficiency (Figure 1b) whereas the dotted lines refer to the correlation for radial turbine efficiency (Figure $2 b$ ). The optimum cycle maximum pressure of ORCs equipped with radial turbines is close but slightly higher than that of axial turbines. At the optimum maximum pressure the radial turbine efficiency is higher than the axial one for all working fluids. The difference is more significant at high $V R$ (see R236fa) and low $V H$ (see iC4).

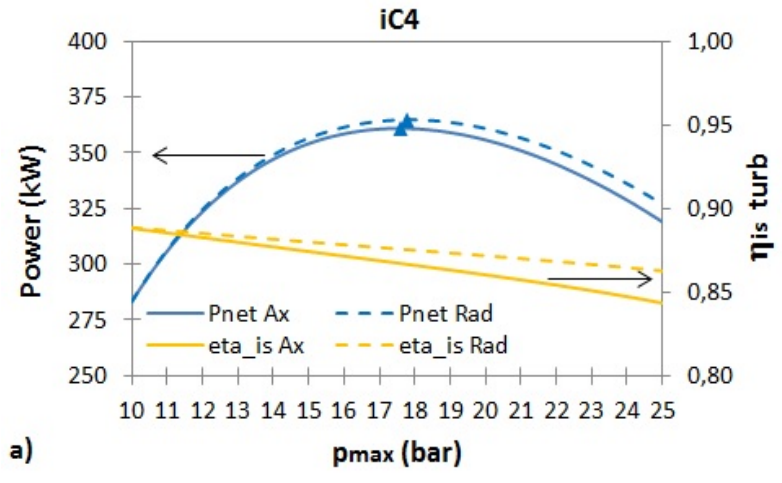

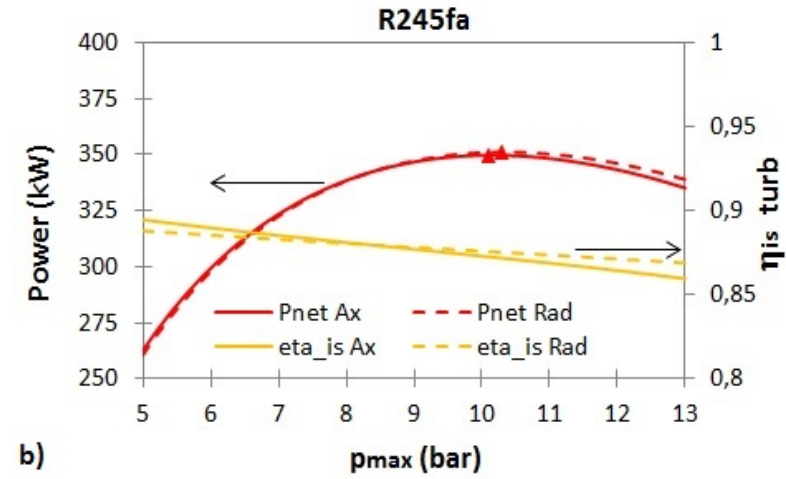
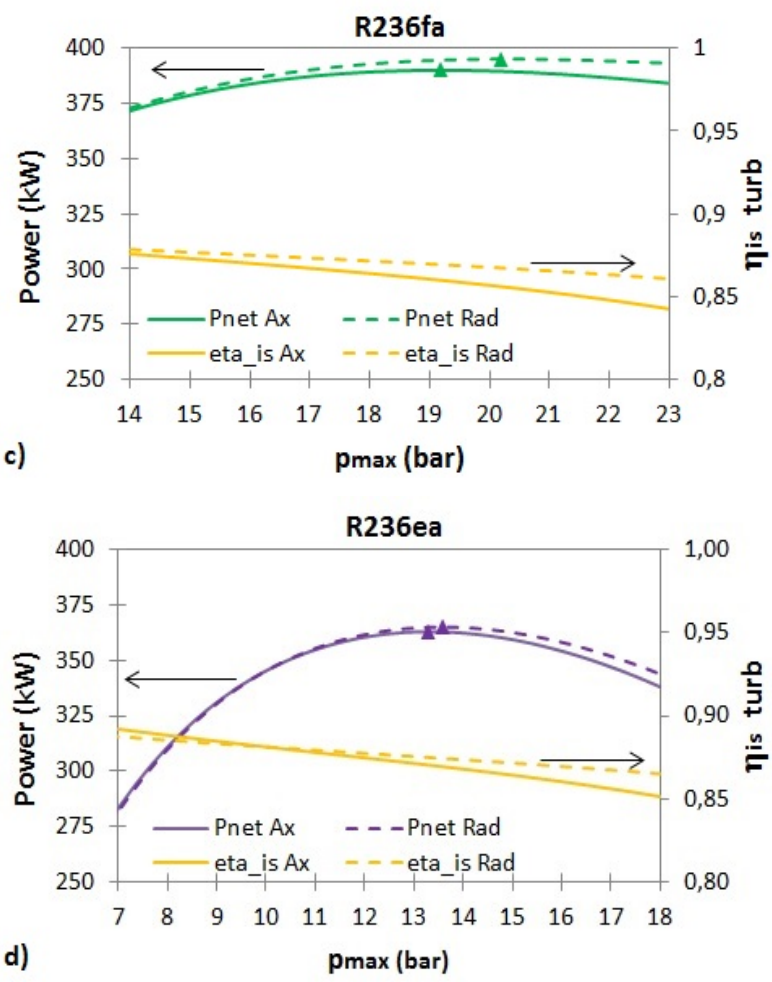

Figure 8. Variation of net power output and turbine isentropic efficiency for iC4, R245fa, R236fa, R236ea. The solid lines refer to an axial turbine stage whereas the dotted lines refer to a radial turbine stage.

\section{Conclusions}

Several thermodynamic optimization studies of ORCs appeared in the recent literature aimed at selecting the best working fluids and ORC design parameters. Turbine design is generally considered after the ORC thermodynamic optimization is performed. The recent literature about design of turbines for ORC applications shows how the values of the volumetric expansion ratio $V R$ and size parameter $V H$ greatly affect the turbine efficiency. These parameters depend on fluid properties, which are consequently involved in both cycle and turbine performance evaluation.

These concepts are used in this paper by suggesting an optimization procedure for the design parameters of ORCs which embeds a correlation of turbine efficiency with $\mathrm{VH}$ and VR. In this way the fluid properties are taken into account at each step of the optimization process. The procedure is applied to optimize the ORC performance using four working fluids (iC4, R245fa, R236fa, R236ea) assuming an inlet temperature of the heat source (geothermal brine) equal to $150^{\circ} \mathrm{C}$. Two geothermal fluid 
mass flow rates are considered (100 and $10 \mathrm{~kg} / \mathrm{s}$ ) and both axial and radial turbine efficiency correlations are introduced in the design optimization. Thermodynamic cycles are subcritical with saturated vapour at the turbine inlet and a fixed condensing temperature. The maximum cycle high pressure is taken as the decision variable in the optimization problem. Results show that R236fa achieves the highest power output, in spite of the lowest turbine isentropic efficiency. The inclusion of efficiency correlations for either axial or radial turbines modifies more or less the optimum cycle maximum pressure depending on the working condition on the $V H-V R$ chart. Thus, the common assumption of fixed isentropic efficiency in thermodynamic optimization may give non proper results about the optimum working fluids and design parameters. The comparison between axial and radial turbines shows that radial turbines hold higher isentropic efficiencies at high $V R$, which results in higher net power output and a shift of the optimum pressure at higher values compared to axial flow turbines. This optimization procedure is general because it is valid for single stage axial and radial inflow turbines as well to multi-stage machines and for any kind of fluid. Practical applications are needed to get experimental data from new turbine designs in order to update the charts that are presently available.

\begin{tabular}{|c|c|}
\hline \multicolumn{2}{|c|}{ Nomenclature } \\
\hline$A x$ & axial turbine \\
\hline$C_{m}$ & meridional velocity, $\mathrm{m} / \mathrm{s}$ \\
\hline$D$ & turbine diameter, m \\
\hline$d_{s}$ & specific diameter \\
\hline eta_is & turbine isentropic efficiency \\
\hline$m$ & mass flow rate, $\mathrm{kg} / \mathrm{s}$ \\
\hline$\dot{m}$ & mass flow rate, kg/s \\
\hline$n$ & rotational speed, rpm \\
\hline Ns & specific speed \\
\hline$P$ & power, kW \\
\hline$p$ & pressure, bar \\
\hline pump & feed pump \\
\hline $\operatorname{Rad}$ & radial turbine \\
\hline rpm & revolutions per minute \\
\hline$T$ & temperature, ${ }^{\circ} \mathrm{C}$ \\
\hline turb & turbine \\
\hline$s$ & entropy, J/kg-K \\
\hline$U$ & peripheral speed, m/s \\
\hline$v$ & specific volume, $\mathrm{m}^{3} / \mathrm{kg}$ \\
\hline$V H$ & size parameter, $\mathrm{m}$ \\
\hline$V R$ & volumetric expansion ratio \\
\hline$\dot{V}_{\text {in }}$ & volumetric flow rate at turbine inlet, $\mathrm{m}^{3} / \mathrm{s}$ \\
\hline$\dot{V}_{\text {out }}$ & volumetric flow rate at turbine outlet, $\mathrm{m}^{3} / \mathrm{s}$ \\
\hline$\phi$ & flow coefficient \\
\hline$\psi$ & stage loading coefficient \\
\hline$\Delta h_{0}$ & total enthalpy drop, J/kg \\
\hline$\Delta h_{i s}$ & isentropic enthalpy drop, $\mathrm{J} / \mathrm{kg}$ \\
\hline$\eta_{i s}$ & turbine isentropic efficiency \\
\hline$\eta_{T S}$ & total to static turbine efficiency \\
\hline$\omega$ & rotational speed, rad/s \\
\hline
\end{tabular}

Subscripts

CR critical

$\begin{array}{ll}\text { in } & \text { inlet } \\ \text { opt } & \text { optimum } \\ \text { out } & \text { outlet } \\ \text { max } & \text { maximum } \\ \text { GEO } & \text { geothermal fluid }\end{array}$

\section{References}

[1] H. Chen, D.Y. Goswami, M.M. Rahman, E.K. Stefanakos, Energetic and exergetic analysis of $\mathrm{CO}_{2}$ and R32-based transcritical Rankine cycles for lowgrade heat conversion, Appl Energ, 88, 2802-2808, 2011.

[2] N. Yamada, M.N.A. Mohamad, T.T. Kien, Study on thermal efficiency of low- to medium-temperature organic Rankine cycles using HFO-1234yf, Renew Energ, 41, 368-375, 2012.

[3] B.F. Tchanche, G. Papadakis, G. Lambrinos, A. Frangoudakis, Fluid selection for a low-temperature solar organic Rankine cycle, Appl Therm Eng, 29, 24682476, 2009.

[4] Y. Dai, J. Wang, L. Gao, Parametric optimization and comparative study of organic Rankine cycle (ORC) for low grade waste heat recovery, Energ Convers Manage, 50, 576-582, 2009.

[5] A. Schuster, S. Karellas, R. Aumann, Efficiency optimization potential in supercritical Organic Rankine Cycles, Energy, 35, 1033-1039, 2010.

[6] B. Saleh, G. Koglbauer, M. Wendland, J. Fischer, Working fluids for low-temperature organic Rankine cycles, Energy, 32, 1210-1221, 2007.

[7] Y.-J. Baik, M. Kim, K.C. Chang, S.J. Kim, Power-based performance comparison between carbon dioxide and R125 transcritical cycles for a low-grade heat source, Appl Energ, 88, 892-898, 2011.

[8] F. Marcuccilli, D. Thiolet, Optimizing Binary Cycles in Radial Inflow Turbines, GRC Transactions, 33, 737743, 2009.

[9] Z. Shengjun, W. Huaixin, G. Tao, Performance comparison and parametric optimization of subcritical Organic Rankine Cycle (ORC) and transcritical power cycle system for low-temperature geothermal power generation, Appl Energ, 88, 2740-2754, 2011.

[10] X.D. Wang, L. Zhao, Analysis of zeotropic mixtures used in low-temperature solar Rankine cycles for power generation, Sol Energy, 83, 605-613, 2009.

[11] G.J. Zyhowski, A.P. Brown, A. Achaichia, "HFC245fa Working Fluid in Organic Rankine Cycle - A Safe and Economic Way to Generate Electricity from Waste Heat", in ECOS 2010: Proc. of the 23rd Int. Conf. on Efficiency, Cost, Optimization, Simulation and Environmental Impact of Energy, Lausanne, CH, 2010.

[12] E. Sauret, A.S. Rowlands, Candidate radial-inflow turbines and high-density working fluids for geothermal power systems, Energy, 36, 4460-4467, 2011.

[13] H. Moustapha, M.F. Zelesky, N.C. Baines, D. Japikse, Axial and radial turbines. White River Junction: Concepts NREC, 2003.

[14] D. Japikse, N.C. Baines, Introduction to turbomachinery. Norwich (VT): Concepts ETI, 1994.

[15] E. Macchi, A. Perdichizzi, Efficiency prediction for axial-flow turbines operating with nonconventional fluids, J Eng Gas Turb Power, 103, 718- 724, 1981. 
[16] A. Perdichizzi, G. Lozza, "Design criteria and efficiency prediction for radial inflow turbines", in Proc. of the Gas Turbine Conf. and Exhibition, Anaheim, CA (USA), 1987.

[17] E. Macchi, “The choice of working fluid: the most important step for a successful Organic Rankine Cycle (and an efficient turbine)" [Tech. Presentation], in: $2^{\text {nd }}$ Int. Seminar on ORC Power Systems, De Doelen, Rotterdam, NL, 2013.

[18] J. Harinck, T. Turunen-Saaresti, P. Colonna, S. Rebay, J. van Buijtenen, Computational Study of a HighExpansion Ratio Radial Organic Rankine Cycle Turbine Stator. J Eng Gas Turb Power, 132(5), 2010.

[19] O. Badr, S.D. Probert, P.W. O’Callaghan, Selecting a Working Fluid for a Rankine-Cycle Engine, Appl Energ, 21, 1-42, 1985.

[20] S.L. Dixon, C.A. Hall, Fluid Mechanics and Thermodynamics of Turbomachinery, $6^{\text {th }}$ Ed. Burlington: Butterworth Heinemann, 2010.
[21] O.E. Balje, Turbomachines: a guide to design, selection and theory. John Wiley and Sons, New York, 1981.

[22] N. Baines. (2013). How to Choose a Turbine [Online]. Available:

http://www.conceptsnrec.com/Resources/Webinars-OnDemand.aspx

[23] G. Angelino, M. Gaia, E. Macchi, “A review of Italian activity in the field of ORCs", in Proc. of the Int. VDI Seminar, Zurich, CH, 1984.

[24] G. Manente, R. Field, R. DiPippo, J.W. Tester, M. Paci, N. Rossi, "Hybrid Solar-Geothermal Power Generation to Increase the Energy Production from a Binary Geothermal Plant", in Proc. of the ASME Int. Mechanical Engineering Congress \& Exposition (IMECE), Denver, CO (USA), 2011. 